\title{
Techniques of Nerve-Sparing and Potency Outcomes Following Robot-Assisted Laparoscopic Prostatectomy
}

\author{
Sanket Chauhan, Rafael F. Coelho, Bernardo Rocco, Kenneth J. Palmer, Marcelo A. Orvieto, \\ Vipul R. Patel
}

Global Robotics Institute (SC, RFC, BR, KJP, MAO, VRP), Florida Hospital - Celebration Health, Department of Urology, University of Central Florida School of Medicine, Celebration, Florida, USA, Division of Urology (RFC), University of Sao Paulo, SP, Brazil and Division of Urology, European Institute of Oncology, Milan, Italy

\begin{abstract}
Purpose: Nerve sparing radical prostatectomy is the gold standard for the treatment of prostate cancer. Over the past decade, more and more surgeons and patients are opting for a robot-assisted procedure. The purpose of this paper is to briefly review different techniques and outcomes of nerve sparing robot assisted laparoscopic prostatectomy (RALP).

Materials and Methods: We performed a MEDLINE search from 2001 to 2009 using the keywords "robotic prostatectomy", "cavernosal nerve", "pelvic neuroanatomy", "potency", "outcomes" and "comparison". Extended search was also performed using the references from these articles.

Results: Several techniques of nerve sparing are available in literature for RALP, which have been described in this manuscript. These include, "the veil of Aphrodite", "athermal retrograde neurovascular release", "clipless antegrade nerve sparing" and "clipless cautery free technique". The comparative and the non comparative series showing outcomes of RALP have been described in the manuscript.

Conclusions: The basic principles for nerve sparing revolve around minimal traction, athermal dissection, and approaching the correct planes. It has not been documented if any one technique is better than the other. Regardless of technique, patient selection, wise clinical judgment and a careful dissection are the keys to achieve optimal oncological outcomes following RALP.
\end{abstract}

Key words: prostatic neoplasm; prostatectomy; robotics; outcomes

Int Braz J Urol. 2010; 36: 259-72

\section{INTRODUCTION}

Prostate cancer is the most commonly diagnosed cancer among men in United States. According to a recent estimate, 192,280 (25\%) new patients will be diagnosed with prostate cancer in the year 2009, making it the most commonly diagnosed cancer in men and the second most common cause of death in men (1). Retropubic Radical Prostatectomy (RRP) is still the gold standard for the treatment of organ confined prostate cancer, offering better survival rates, when compared to conservative management (2). With the advances in Minimally Invasive Surgery (MIS) and its application to the Urology field, Schuessler et al. performed the first Laparoscopic Radical Prostatectomy (LRP) in 1992 (3). However, the procedure was associated with a long learning curve related to the reduced range of motion, loss of 
3D vision, counter-intuitive hand eye coordination, poor surgeon ergonomics and loss of tactile feedback. The recent introduction of advanced robotic devices such as the da Vinci Surgical System (Intuitive Surgical, Inc., Sunnyvale, CA) to the field of urologic surgery has added new hopes of reducing operative times and the learning curve for minimally invasive prostatectomy. Binder and Kramer (4) performed the first Robot Assisted Laparoscopic Prostatectomy. (RALP) in 2000 and since then, it has become an increasingly popular treatment option. The technique for this procedure has been described earlier (5) However, it is controversial whether RALP has any specific advantage over open or laparoscopic procedures. Some studies suggest that RALP has clear advantage over conventional procedures even in during the learning curve, (6) while others show no such advantage (7).

Postoperative potency and continence rates are used as surrogates to mark the functional efficacy of this procedure. However, it is still extremely difficult to precisely predict the outcomes after radical prostatectomies . The potency rates, particularly, depend on many factors such as pre-operative erectile function, patient co-morbidities, type and extent of nerve sparing, patient's age, frequency of intercourse, use of medications and the experience of the surgeon (8). This list is not exclusive and there is no foolproof "formula" to ascertain potency recovery even in younger patients.

Many technical refinements and approaches to nerve sparing during RALP have been described in recent years aiming to improve the potency outcomes after surgery. In this review we discuss these techniques and present the potency outcomes after RALP currently available in medical literature.

\section{MATERIALS AND METHODS}

A MEDLINE search was performed between 2000 and 2009 using the keywords "robotic prostatectomy", "nerve sparing", "cavernosal nerve", "pelvic neuroanatomy", "potency", "outcomes" and "comparison". We performed additional hand searches based on references from relevant review articles (9-11). Studies published only as abstracts and reports from meetings were not included in the review. Only studies published in English language were included. Comparative and non-comparative studies were included. Outcomes were tabulated and analyzed from the resulting articles.

\section{BASIC ANATOMICAL PRINCIPLES FOR NERVE SPARING PROCEDURES}

The first mention of neural structures having a role in potency was made as early as 1863 when Eckhard defined nervi erigentus in animal models (12). More than one century later, Walsh in a series of studies described the detailed anatomy of cavernous nerves and its importance in preserving the potency after radical prostatectomy. After tracing the autonomic innervation of the corpora cavernosa in a male fetus and newborn, Walsh and Donker (13) demonstrated that branches of the pelvic plexus that innervate the corpora cavernosa are situated between the rectum and urethra, and penetrate the urogenital diaphragm near or in the muscular wall of the urethra. The neuro-vascular bundle of Walsh (syn: cavernosal nerve, bundle of Walsh or most commonly, just NVB) is a tubular structure that runs dorso-laterally to the prostate as an inferior extension to the pelvic plexus (syn: inferior hypogastric plexus, pelvic ganglion). Based on these findings, he proposed an anatomical concept and modifications for radical prostatectomy (14) where the lateral pelvic fascia was incised anterior to the NVBs, and the lateral pedicle is divided close to the prostate to avoid injury to the branches of the pelvic plexus that accompany capsular vessels of the prostate. This marked a new era in the treatment of prostate cancer where the benefits outweighed the risks for the then highly invasive procedure of radical prostatectomy. Walsh later verified these findings in a 60 year old human cadaver (15).

In 2004, Costello and colleagues (9) demonstrated in their human cadaver studies that most of the NVB descends distally and dorso-laterally to seminal vesicles (posterior nerves), while anterior nerves course along the posterior-lateral border of seminal vesicles (Figure-1). The anterior and posterior nerves of NVB are separated by a distance of $3 \mathrm{~cm}$ at the base of prostate. These run distally towards the apex, converge at mid prostatic level, and then diverge 


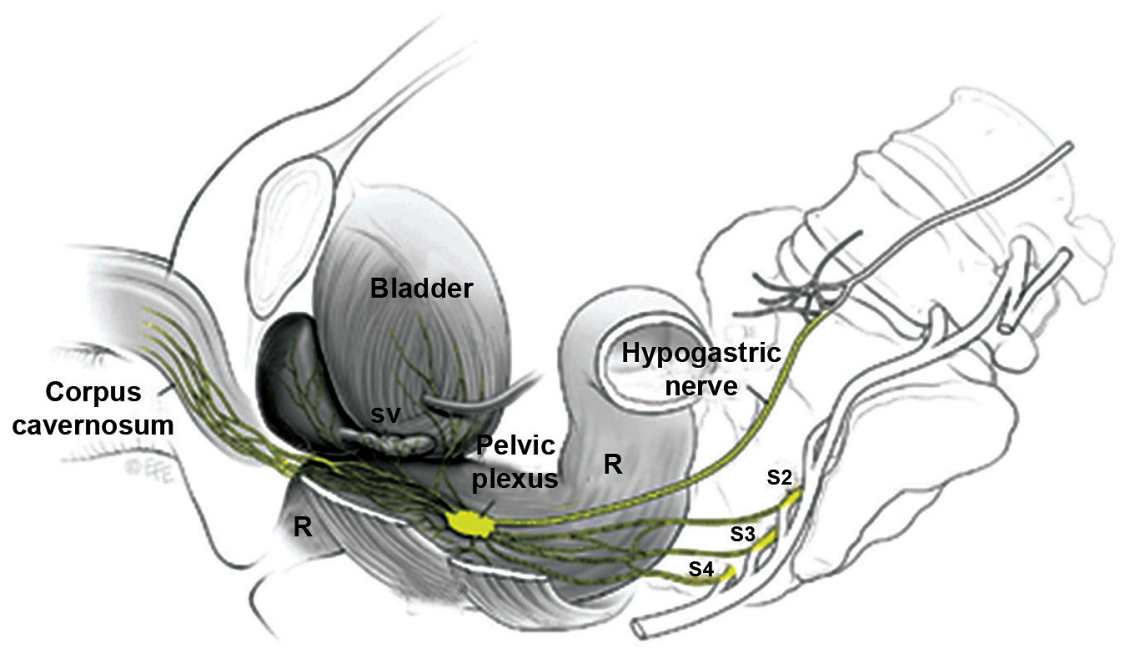

Figure 1 - The pelvic plexus and formation of neurovascular bundles, reprinted from Costello et al. (9) (with permission from WileyBlackwell Publishing).

again as they approach the prostate apex, where it is most variable in course and architecture.

In 2006, Tewari et al. (10) demonstrated in their study on 10 fresh and 2 fixed male cadavers, a tri-zonal neural architecture relevant to robotic prostatectomies. They described the presence of a proximal neurovascular plate (PNP), a predominant neurovascular bundle (PNB) and accessory neural pathways (ANPs). The PNP include vesical and prostatic subdivision of the pelvic plexus and was composed of ganglia and interconnecting nerve fibers which process and relay erectogenic neural signals. The PNB is the classical nerve bundle that carries neural impulses to the cavernosal tissue. It is contained between the layers of lateral pelvic and/or levator fascia, and is postero-lateral to the prostate. The ANPs are putative accessory pathways usually within the layers of lateral pelvic fascia and/or levator fascia and lies posterolateral or anterolateral to the prostate.

\section{The Fascial Planes for Nerve Sparing}

To prevent mechanical and thermal injury during dissection of the NVB, the appropriate plane needs to be developed based on its anatomical relationship with the periprostatic fascial planes. To understand these planes, the knowledge of the anatomy of pelvic fascial structures is necessary. The high magnification offered on a robotic platform enables the surgeon to accurately identify the surgical landmarks and to create and enter the plane of interest. Ayala et al. reviewed 50 specimens from radical prostatectomy for prostate cancer and reported that prostate capsule is not a true capsule but a fibro-muscular band located between glandular units and peri-prostatic connective tissue (11). The endopelvic fascia is a multilayer fascia that covers the prostate and the bladder and is linked to the prostate capsule by collagen fibers, finally inserting in the form of puboprostatic ligaments to the pubic bone. The part of endopelvic fascia that covers the prostate is called the prostatic fascia. The outer part of endopelvic fascia is called Levator fascia or Lateral Pelvic fascia. Denonvilliers fascia is the fascia that covers the rectum posterior to the prostate. Martỉnez-Piñeiro et al. (16) describe an anterior extension to Denonvilliers fascia which fuses laterally with the endopelvic fascia.

An intrafascial plane is the plane between the prostate capsule and the prostatic fascia. Hence, during an intrafascial dissection, the endopelvic fascia is incised only ventrally, medial to the puboprostatic ligaments (17). The interfascial plane is the plane between the prostatic fascia and the lateral pelvic fascia. Posteriorly, the interfascial plane exists as the 
avascular plane between the prostatic fascia and the Denonvilliers fascia and between the prostatic fascia and the anterior extension of Denonvilliers fascia. Most of the NVBs lie between the anterior extension of the Denonvilliers fascia and the levator fascia. Hence complete preservation of NVBs is achieved with either intrafascial or interfascial dissection. Dissection along extrafascial plane is right through the NVBs and might enable some preservation of the neural tissue or none (Figure-2).

\section{Significance of Athermal Dissection}

It is important to dissect the NVBs without the use of thermal energy because these nerves have unmyelinated structure that makes them vulnerable to the dissipated thermal energy. In their studies on canine models, Ong and associates assessed the erectile function acutely after the surgery and after 2 weeks of survival by measuring peak intracavernous pressures in response to cavernous nerve stimulation
(18). The use of monopolar or bipolar sources in the vicinity of the prostate during dissection of the neurovascular bundle was clearly associated with a significantly decreased erectile response to cavernous nerve stimulation.

Subsequently, Ahlering et al. in their case control series demonstrated the effect of thermal energy on the return of sexual activity (19). Potency was defined as "erections hard enough for vaginal penetration with or without the use of PDE-5 inhibitors". In the cautery group, $14.7 \%$ of patients were potent after 9 months (UNS-10\%; BNS-16.7\%) and 63.2\% were potent at 24 months (UNS-50\%; BNS-67.9\%), as compared to $69.8 \%$ (UNS-56.3\%; BNS-72.8\%) and $92 \%$ (UNS-83.3\%; BNS- 92\%) respectively for the cautery free group.

In a recent modification, Ahlering et al. (20) reported hypothermic nerve sparing on 50 consecutive patients. Pelvic cooling was achieved using cold irrigation and an endorectal cooling balloon cycled with $4^{\circ} \mathrm{C}$ saline. The lubricated balloon was inserted via the anus, and an esophageal probe was used to obtain the

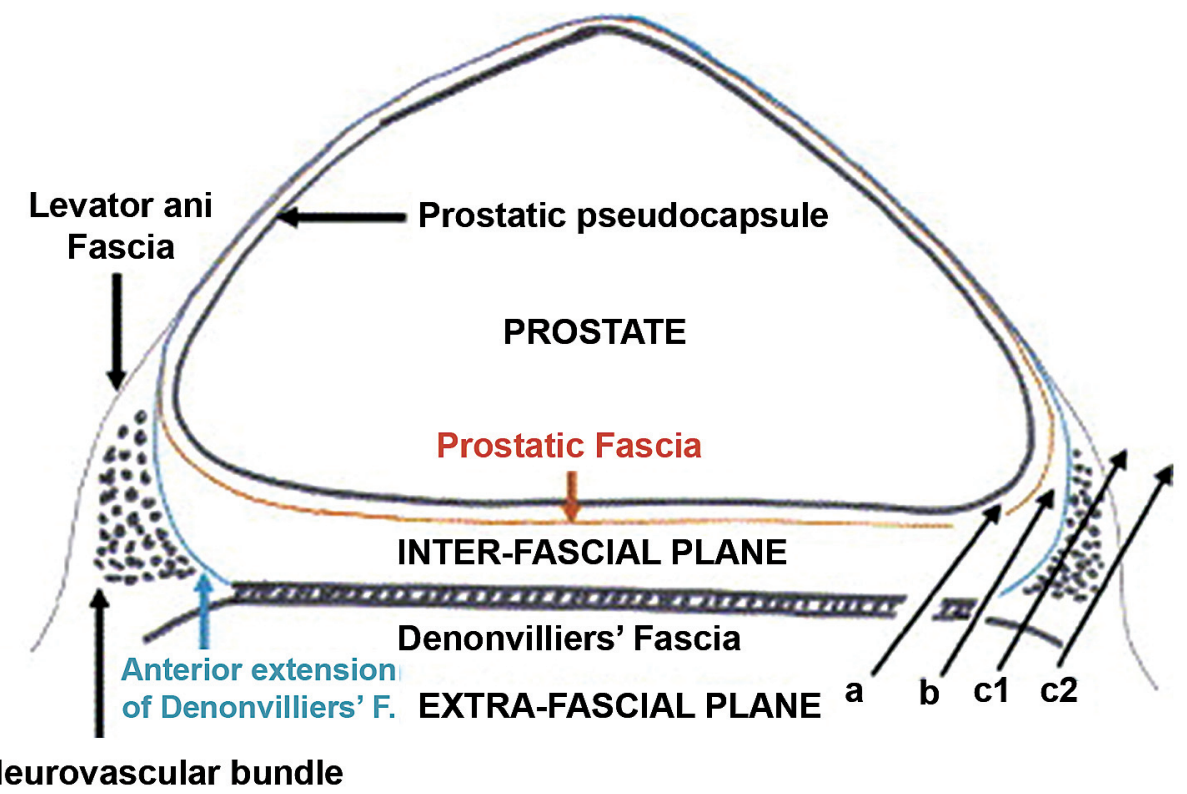

Figure 2 - Axial view of prostatic fascial anatomy. $a=$ intrafascial plane; $b=$ interfascial plane; $c 1=$ extrafascial plane with partial preservation of neurovascular bundle; $c 2=$ extrafascial plane with no preservation of neurovascular bundle. (9) (with permission from Elsevier publishing). 
intracorporeal temperature readings directly from the surface of anterior rectum/NVBs. This has shown to significantly improve post-operative continence. The potency outcomes are still awaited.

Gianduzzo et al. (21) have recently evaluated cavernous nerve function following KTP laser dissection and compared outcomes to those of ultrasonic shears and cold scissor dissection. Peak intracavernous pressure upon cavernous nerve stimulation was expressed as a percent of mean arterial pressure. This was measured acutely and at 1 month after the surgery on a canine model. Thermal spread from the KTP laser and ultrasonic shears was assessed histologically ex vivo in a harvested peritoneum. The median depth of acute laser injury was $600 \mu \mathrm{m}$ compared to 1.2 $\mathrm{mm}$ for ultrasonic shear dissection and $450 \mu \mathrm{m}$ crush injury due to the athermal technique. Thermography revealed less collateral thermal spread from the laser than from the ultrasonic shears (median greater than $60^{\circ} \mathrm{C}$ thermal spread 1.07 vs. $6.42 \mathrm{~mm}, \mathrm{p}<0.01$ ). Hence KTP laser had similar outcomes as athermal technique and was superior to ultrasonic shears for preserving cavernous nerve function.

\section{TECHNIQUES OF NERVE SPARING AND POTENCY OUTCOMES FOLLOWING RALP}

The nerve sparing is an important step in radical prostatectomy that determines the functional outcomes of the procedure. Hence every attempt should be made to preserve the NVBs. The surgical dilemma however is that an ambitious nerve sparing might lead to higher positive surgical margin (PSM) rate. Although some recent studies have shown the feasibility of using Optical Coherence Tomography (OCT) on the pathological specimen and predicting the PSM and Extra capsular Extension (ECE) rate, this technology has not yet diffused into the clinical practice (22). Hence a wise clinical decision should be made before proceeding with the nerve sparing.

The approach to nerve sparing can be from the prostate base to apex (antegrade) or from apex to base (retrograde), unilateral or bilateral, partial or full. These terms are self explanatory. The mechanical trauma to the nerves might also be caused by the method of handling of the pedicles which are essentially a vascular structure, but very closely related to NVBs. These pedicles can be controlled by clamping, clipping or suturing. Several nerve sparing techniques have been described in literature.

\section{The 'Veil of Aphrodite' Technique (Syn: high anterior release, curtain dissection)}

Aphrodite was the Greek Goddess of love, beauty and sexual ecstasy. The veil is an area of cavernosal nerves that extends from the posterolateral to the anterolateral surface of the prostate like a curtain $(23,24)$. The avascular interfascial plane between the posterior prostatic fascia and Denonvilliers fascia is extended as distally as possible towards the apex, and laterally to expose pedicles which lie anterior to the pelvic plexus and NVBs. The pedicles are divided by clipping or bipolar cauterization and after appropriate countertractions, the prostatic fascia is incised anteriorly to enter the intrafascial plane. Meticulous sharp and blunt dissection on the fascia is performed athermally until the entire peri-prostatic fascia is released like a veil hanging from the pubo-uretheral ligaments (Figure-3).

In their series published in 2007, Menon et al. selected 1142 out of 2652 patients who underwent RALP at their institute with at least 1 year follow-up. Potency was defined as the ability to have erections adequate enough for vaginal penetration. $70 \%$ of patients who were potent before the surgery (SHIM $>21$ ) and had a BNS, were able to achieve sexual intercourse after surgery with or without the use of PDF-5 inhibitors (25).

The veil technique has recently been modified by these authors in an attempt to preserve the pubovesical ligaments and the Dorsal Venous Complex (DVC). The technical modification consists of extending the interfascial dissection anteriorly and intrafascially between 11 o'clock and 1 o'clock position, ("superveil" sparing). Cold scissors or hot monopolar hook is used where the prostatic fascia is adherent to the capsule. In 85 patients who used phosphodiesterase- 5 inhibitors, and attempted sexual intercourse, $94 \%$ had erections sufficient for penetration on a median follow-up of 18 months (26). 


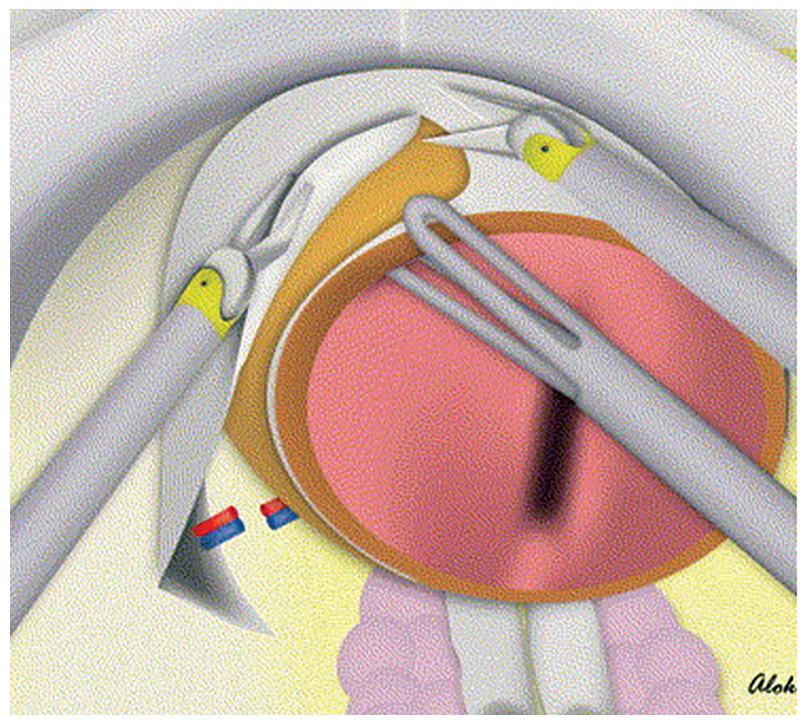

Figure 3 - Place of dissection for 'veil of Aphrodite' (from ref. 21, with permission from Elsevier publishing).

\section{Athermal Early Retrograde NVB Release During Antegrade Prostatectomy}

The conventional approach to nerve sparing during laparoscopic and robotic prostatectomy has been from the prostate base to apex (antegrade). However, the NVB is closely and complexly related to the base of the prostate, which might be at risk of inadvertent trauma during an antegrade approach to nerve sparing. Based on this philosophy, Patel et al. (27) have reported a unique technique whereby the NVBs are approached in a retrograde fashion (from apex to base). The lateral pelvic fascia is incised at the level of apex and the mid portion of prostate and an avascular plane is developed between the NVBs and the prostatic fascia. This plane is extended posteriorly until it meets the interfascial plane developed initially between the prostate and the rectum. The entire dissection is carried out athermally. The vascular pedicle is ligated with a hemolock clip which is placed above the NVB. Releasing the bundle early and delineating its path avoid inadvertent damage at his point. It is then released distally to the level of pelvic floor to avoid damaging it during the apical dissection or vesico-urethral anastomosis.

These authors published their series of 397 consecutive patients out of which 233 (58.7\%) had a
BNS and $51(12.8 \%)$ had a UNS using this modified technique. Potency was defined as having erections sufficient enough for vaginal penetrations with or without the use of PDE-5 inhibitors. Patients with preoperative Sexual Health Inventory for Men (SHIM) score higher than 21 who had at least 3 months follow-up $(\mathrm{n}=98)$ showed a potency rate of $87.7 \%$ and for the patient group with SHIM between 17 and 21, the potency rate was $73 \%$.

\section{Clipless Antegrade Nerve Sparing}

Chien et al. (28) have described clipless antegrade technique for nerve sparing where they use a combination of cold cutting with judicious use of monopole and bipolar energy during this approach. The interfascial plane is created posterior to prostate to release it from its posterior attachments on the rectum. This plane is continued towards the apex along the midline. The vascular pedicles are swept off the prostatic pedicles using a combination of blunt and sharp cold scissors in a medial to lateral dissection. The vascular pedicles are then mobilized in the anterior direction until its distal end where the small vessels that penetrate into the prostate capsule are identified. These end vessels, which are very tiny and no more than $1 \mathrm{~mm}$ is diameter, are cauterized using bipolar cautery eliminating the need of bulk clipping. The damage to the nerves due to dissipating thermal energy is theoretically diminished as the distance between NVBs and the prostate capsule is increased. Further mobilization of NVBs is achieved by brushing the vascular pedicles off the prostate. Hence, the prostatic fascia, NVBs, and the prostate pedicle are 'peeled of' the prostate in one piece until the urethra is reached, and NVB preservation is achieved.

In their study Zorn et al. prospectively followed 300 patients over 24 months (29). UNS was performed in 79 patients out of whom 66 were potent preoperatively (SHIM $>20$ ), and BNS was performed on in 179 patients of which 161 where potent preoperatively. Potency was defined as the ability to achieve erections sufficient for vaginal penetration with or without the use of oral PDE5 inhibitors. In the UNS group, $52 \%$ of the patients were potent at the end of 6 months while $62 \%$ were potent at the end of 24 
months. For the group with BNS, these figures were $53 \%$ and $83 \%$ respectively.

\section{Clipless Cautery Free Technique}

Ahlering et al. have described an approach to nerve sparing using vascular clamps and sutures for pedicle control, hence claiming to protect the NVBs both from mechanical and thermal trauma (30). After the posterior dissection and releasing the prostate from its posterior attachments, the vascular pedicles are identified. These are clamped using $30 \mathrm{~mm}$ bulldog clamps laparoscopically and at least $1 \mathrm{~cm}$ from the prostate. The dissection is strictly athermal beyond this point. The pedicles are ligated using a running 3-0 polyglycolic acid suture. The clamp is then removed and the suture is used to display remaining vessels. Any pulsatile bleeding, if present along the length of NVBs is controlled by suturing. The pedicles are then divided, the lateral pelvic fascia is incised and the NVBs are gently released off the prostate, down till urethra in an antegrade fashion.

In a recent series published in 2009, Ahlering et al. selected 58 patients who were less than 65 years with an International Index of Erectile Function (IIEF)-5 score greater than 21, and followed them over 2 years prospectively (31). Potency was defined as having erections adequate for vaginal penetration with or without the use of oral PDE-5 inhibitors. The authors reported a potency rate of $40 \%$ at 3 months and $80 \%$ at 2 years for those who had UNS while for BNS, the rate was $29.3 \%$ and $93 \%$ respectively.

\section{OTHER POTENTIAL TECHNIQUES TO IMPROVE POTENCY OUTCOMES}

In addition to the techniques described above, several other techniques have been defined in other models that can be utilized in RALP. Gill et al. (32) have described a 'Clamp and Suture technique with ultrasound guidance' for laparoscopic prostatectomies. They used $25 \mathrm{~mm}$ atraumatic bulldog laparoscopic clamp, 4-0 polyglactin suture, and intra-operative transrectal ultrasound (TRUS) imaging before and during the application of bulldog clamps, and at the prostatectomy completion. Hence they evaluate the dimension of NVB, number of visible vessels and resistive index of the arterial flow within the NVBs. This technique completely eliminates all electrocautery, USG thermal energy, clips and bioadhesives.

Peabody et al. have described a technique where the hydrodissection of the neurovascular bundle was performed athermally by injecting 1:10000 epinephrine solution diluted with $0.9 \% \mathrm{NS}$ into the lateral prostatic pedicle with an injection cannula needle. They performed robotic BNS in 10 patients and the series showed favorable peri-operative outcomes. However, the potency data is still awaited for these patients (33).

\section{POTENCY OUTCOMES IN OTHER NON COMPARATIVE RALP SERIES}

The definition of potency has not been consistent in the literature. The SHIM score that is used to objectively estimate the degree of erectile dysfunction is not an effective marker for potency. Most surgeons however prefer to define potency as erections sufficient to enable penetration with or without the use of oral medications (phosphodiesterase-5 inhibitors). The potency rates as reported in several studies ranges from $21.1 \%$ to $87 \%$ at 12 months post RALP (Table1). However, these studies used different methods for patient selection and time for follow up, and some of these were reported early during the learning curve (34). Ahlering et al. have demonstrated that potency is inversely proportional to the prostate weight (35). Out of 300 consecutive men who underwent RALP by a single surgeon, they identified 139 men $\leq 65$ years with IIEF-5 $>21$. Following RALP, these were grouped according to the prostate weight and prospectively followed up over 3 months. It was found that the return to potency was inversely proportional to prostate size as $65.5 \%$ of patients who had prostate weight $\leq 35 \mathrm{~g}$ were potent at 3 months vis-à-vis $14.3 \%$ who had prostate weight $>85 \mathrm{~g}$. They hypothesized that 1) better visualization of surgical arena due to small prostate size might allow for more preservation of nerve volume and 2) smaller prostate might reduce traction or vascular injury. In another 2 year 


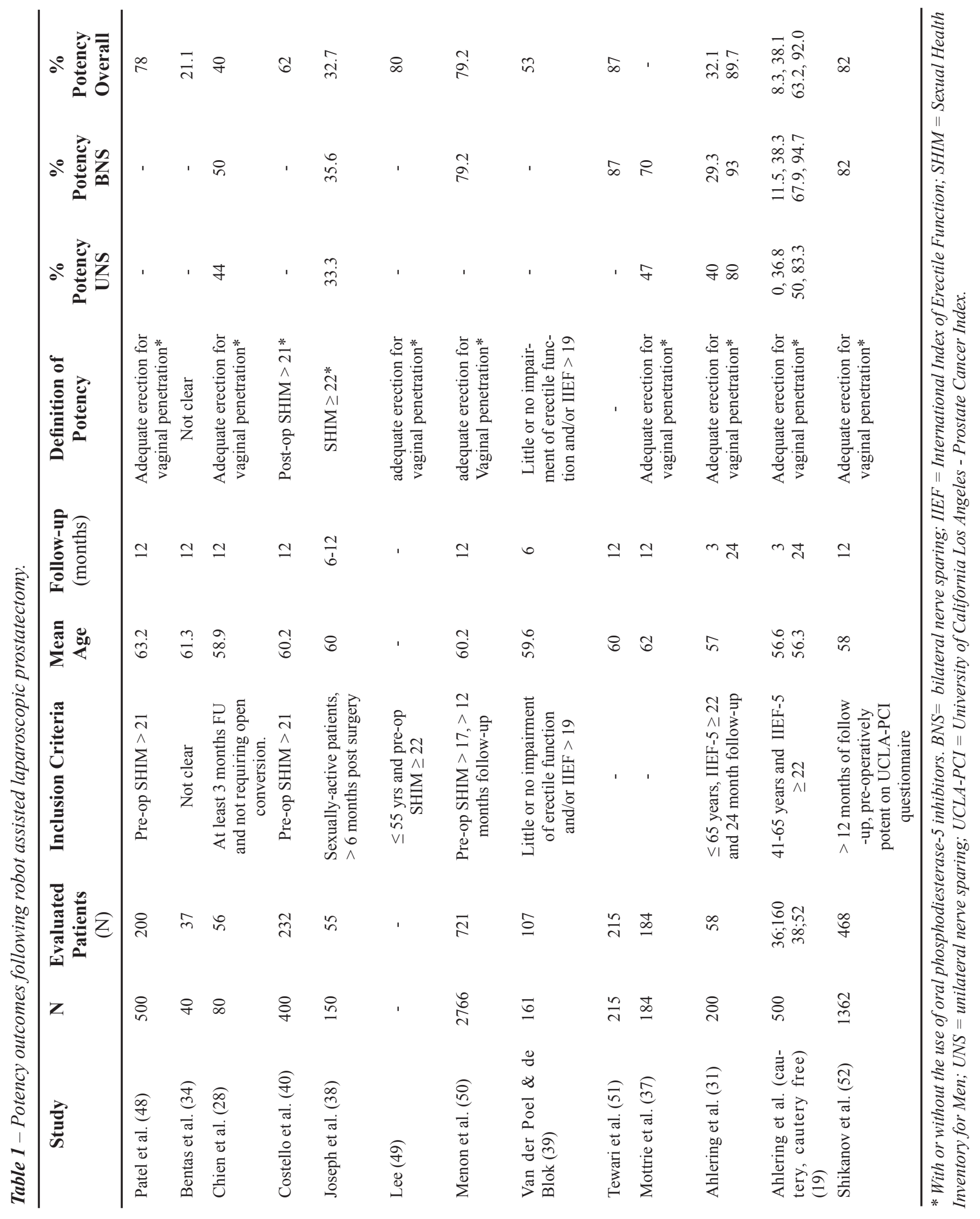


prospective follow-up study, these authors reported that doubling the preserved nerve volume increased the potency by 1.36 times (UNS 50\% vs. BNS 68\%) for the group where cautery was used, and by 1.15 times (UNS 80\% vs. BNS 93\%) where cautery free technique (CFT) was used. Furthermore, the quality of erections (as estimated by IIEF-5) did not vary with the degree of NS, suggesting an important role of neural 'cross over' (19).

In another study, Mendiola et al. have reported that younger men are likely to have earlier return of potency as compared to older men (36). They classified the study population into 3 groups according to their age: $<50 \mathrm{yrs}, 50-59$ yrs and $\geq 60$ years. Younger men $(<50$ yrs.) achieved subjective potency earlier (mean 88 days) as compared to older groups (107 and 105 days respectively, $\mathrm{P}=0.01$ ). Potency rates in the younger men were also significantly higher at 3 and 6 months $(\mathrm{P}=0.04$ for both $)$, and this trend continued upto 12 months. However, no statistical significance was noted at this time, probably due to compromised power of the study.

In their retrospective series of 183 patients, Mottrie et al. have reported the post-operative sexual outcomes over a median follow-up of 6 months (37). Potency was defined as the ability to have erections adequate enough for vaginal penetration with or without the use of PDE5 inhibitors. A total of $81 \%$ of the patients younger than $60 \mathrm{yr}$ and $51 \%$ of patients older than 60 years who received a nerve-sparing procedure were potent postoperatively. The potency rates were $47 \%$ and $70 \%$ for patients who had received a UNS and a BNS respectively. These results were statistically significant.

Some researchers have used a different definition of potency. In their series of 150 patients, Joseph et al. defined potency to be SHIM score > 22 (38). Only those patients who were sexually active and had a follow-up of at least 6 months post surgery were included in the study. Using this definition, the potency rates for the UNS and BNS groups were 33.3\% and $35.6 \%$ respectively. In another study, Van der Poel and de Blok defined potency as little or no impairment of erectile function and/or IIEF $>19$ (39). Out of 161 patients that were followed-up, 107 left the inclusion criteria. At 6 months follow-up, the potency rate was $53 \%$. Murphy et al. defined potency as a SHIM score
$>21$ with or without the use of PDE5 inhibitors (40). In their series of 400 patients, $62 \%$ of patients who had a nerve sparing surgery and were previously potent regained potency after the surgery.

\section{POTENCY OUTCOMES IN COMPARATIVE RALP SERIES}

Several groups have compared the outcomes of robotic series with either open or laparoscopic series (Table-2). All these series have demonstrated that the potency outcomes are better in robotic series than in open or laparoscopic series. Tewari et al. compared 100 patients who had RRP with 200 patients who had RALP at their institution (41). Potency was defined as the ability to achieve erections adequate enough for vaginal penetration. Only patients who had a BNS and were potent pre-operatively were included in the study. The patients after RALP had a earlier return to potency as $50 \%$ regained potency at a mean follow up of 180 days after RALP as compared to 440 days after RRPs.

Krambeck et al. compared 588 RRPs with 294 RALPs (42). They defined potency as ability to have erections adequate enough for vaginal penetration with or without oral pharmacological agents. $62.8 \%$ of the patients were potent in the RRP group while $70.5 \%$ were potent in the RALP group at the end of 12 months. In a recent comparative series, Rocco et al. compared 120 patients who had RALP with 240 patients who had open prostatectomy (43). For patients less than 65 years old who had a UNS or a BNS, the authors have reported that $73 \%$ regained potency after 12 months for the RALP group as compared to $48 \%$ for the open group. This difference was statistically significant $(\mathrm{p}<0.001)$.

Hakimi et al. compared 75 LRPs with 75 RALPS at their institution (44). Of these 75 patients in each group, $84 \%$ and $80 \%$ of the LRP and RALP cohort were potent preoperatively, respectively. Potency was defined as the ability to have erections adequate enough for vaginal penetration more than $50 \%$ of the times. Of the patients who had a BNS, $71 \%$ of LRPs and $76.5 \%$ of RALPs were potent at 12 months post surgery. For UNS group, the figures were $40 \%$ and $57.1 \%$ respectively. 


\begin{tabular}{|c|c|c|c|c|c|}
\hline 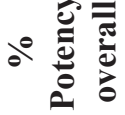 & $\begin{array}{l}\infty \\
\text { iூ }\end{array}$ & ' & $\vec{\nabla} \bar{\sigma}$ & 离京 & ปี \\
\hline 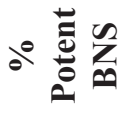 & ' & $\vec{f} \infty$ & ' & 룽 & ' \\
\hline ○。 & ' & ' & ' & o & ' \\
\hline 竞 & 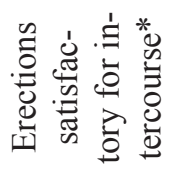 & 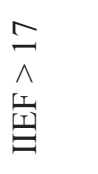 & 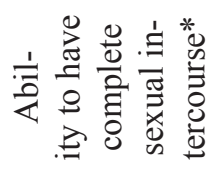 & 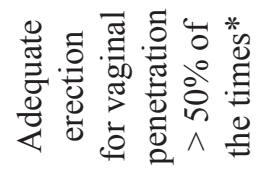 & ' \\
\hline 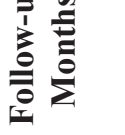 & $\simeq$ & $\simeq$ & $\simeq$ & $\simeq$ & $m$ \\
\hline 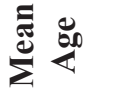 & $\sigma 6$ & 65 & 83 & $\begin{array}{l}0 \\
\text { in in }\end{array}$ & 我 \\
\hline 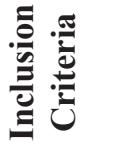 & ' & $\sum_{n}^{n}$ & $\bar{z}$ & 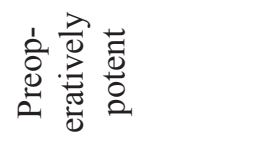 & $\bar{z}$ \\
\hline 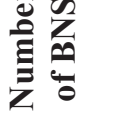 & ' & 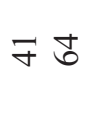 & ' & $\stackrel{n}{+} \bar{n}$ & ¿ \\
\hline 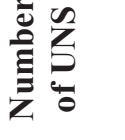 & ' & ' & ' & $\stackrel{\circ}{ }-$ & 으- \\
\hline 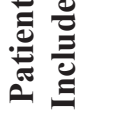 & ' & ' & ' & $\hat{6}:$ & 요 in \\
\hline z & $\begin{array}{l}\infty \\
\infty \\
\infty\end{array}$ & $\ddot{\varrho} \cong$ & $\stackrel{\stackrel{ }{\sim}}{\text { ㅇ }}$ & $\curvearrowleft \curvearrowleft$ & in in \\
\hline 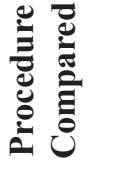 & 忞恋 & 高 & 究 & 点完 & 空宾 \\
\hline$\stackrel{\vec{E}}{\mathbb{E}_{0}}$ & 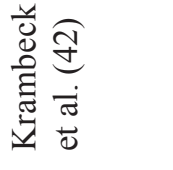 & 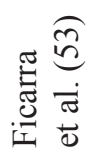 & 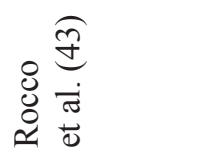 & 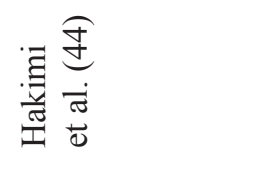 & 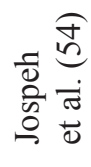 \\
\hline
\end{tabular}




\section{CONCLUSION}

RALP offers patients suffering from prostate cancer a minimally invasive approach to radical prostatectomy. In recent meta-analysis studies it has been implicated that RALP has comparable, if not better outcomes than conventional open and laparoscopic procedures. However, prospective multi-institutional randomized controlled trials need to be designed where the outcomes are evaluated by an independent third party, looking at the outcomes following different techniques. The authors advocate retrograde nerve sparing in an antegrade prostatectomy in order to minimize the risk of unintentional trauma during antegrade approach. However, regardless of the technique, wise clinical judgment should be made intra-operatively when considering nerve sparing and a careful and patient dissection should be performed athermally around the neurovascular bundles.

\section{CONFLICT OF INTEREST}

None declared.

\section{REFERENCES}

1. Cancer Facts and Figures 2009: American Cancer Society. Available online at: http://www.cancer.org/ downloads/STT/500809web.pdf

2. Bill-Axelson A, Holmberg L, Ruutu M, Häggman M, Andersson SO, Bratell S, et al.: Radical prostatectomy versus watchful waiting in early prostate cancer. N Engl J Med. 2005; 352: 1977-84.

3. Schuessler WW, Schulam PG, Clayman RV, Kavoussi LR: Laparoscopic radical prostatectomy: initial shortterm experience. Urology. 1997; 50: 854-7.

4. Binder J, Kramer W: Robotically-assisted laparoscopic radical prostatectomy. BJU Int. 2001; 87: 408-10.

5. Colombo JR Jr, Santos B, Hafron J, Gianduzzo T, Haber GP, Kaouk JH: Robotic assisted radical prostatectomy: surgical techniques and outcomes. Int Braz J Urol. 2007; 33: 803-9.

6. Shah A, Okotie OT, Zhao L, Pins MR, Bhalani V, Dalton DP: Pathologic outcomes during the learning curve for robotic-assisted laparoscopic radical prostatectomy. Int Braz J Urol. 2008; 34: 159-62; discussion 163.
7. Frota R, Turna B, Barros R, Gill IS: Comparison of radical prostatectomy techniques: open, laparoscopic and robotic assisted. Int Braz J Urol. 2008; 34: 259-68; discussion 268-9.

8. Marien T, Sankin A, Lepor H: Factors predicting preservation of erectile function in men undergoing open radical retropubic prostatectomy. J Urol. 2009; 181: 1817-22.

9. Costello AJ, Brooks M, Cole OJ: Anatomical studies of the neurovascular bundle and cavernosal nerves. BJU Int. 2004; 94: 1071-6.

10. Tewari A, Takenaka A, Mtui E, Horninger W, Peschel $\mathrm{R}$, Bartsch G, et al.: The proximal neurovascular plate and the tri-zonal neural architecture around the prostate gland: importance in the athermal robotic technique of nerve-sparing prostatectomy. BJU Int. 2006; 98: 314-23.

11. Ayala AG, Ro JY, Babaian R, Troncoso P, Grignon DJ: The prostatic capsule: does it exist? Its importance in the staging and treatment of prostatic carcinoma. Am J Surg Pathol. 1989; 13: 21-7.

12. Eckhard C: Untersuchungen über die Erection des beim Hunde. Anat Physiol. 1863; 3: 123-66.

13. Walsh PC, Donker PJ: Impotence following radical prostatectomy: insight into etiology and prevention. J Urol. 1982; 128: 492-7.

14. Walsh PC, Lepor H, Eggleston JC: Radical prostatectomy with preservation of sexual function: anatomical and pathological considerations. Prostate. 1983; 4: 473-85.

15. Lepor H, Gregerman M, Crosby R, Mostofi FK, Walsh PC: Precise localization of the autonomic nerves from the pelvic plexus to the corpora cavernosa: a detailed anatomical study of the adult male pelvis. J Urol. 1985; 133: 207-12.

16. Martinez-Pineiro L, Cansino JR, Sanchez C, Tabernero A, Cisneros J, de la Pena JJ: Laparoscopic radical prostatectomy. Differences between interfascial and intrafascial technique. Eur Urol Suppl. 2006; 5: 331.

17. Stolzenburg JU, Schwalenberg T, Horn LC, Neuhaus J, Constantinides C, Liatsikos EN: Anatomical landmarks of radical prostatecomy. Eur Urol. 2007; 51: 629-39.

18. Ong AM, Su LM, Varkarakis I, Inagaki T, Link RE, Bhayani SB, et al.: Nerve sparing radical prostatectomy: effects of hemostatic energy sources on the recovery of cavernous nerve function in a canine model. J Urol. 2004; 172: 1318-22.

19. Ahlering TE, Rodriguez E, Skarecky DW: Overcoming obstacles: nerve-sparing issues in radical prostatectomy. J Endourol. 2008; 22: 745-50. 
20. Finley DS, Osann K, Skarecky D, Ahlering TE: Hypothermic nerve-sparing radical prostatectomy: rationale, feasibility, and effect on early continence. Urology. 2009; 73: 691-6.

21. Gianduzzo TR, Colombo JR Jr, Haber GP, Magi-Galluzzi C, Dall'Oglio MF, Ulchaker J, et al.: KTP laser nerve sparing radical prostatectomy: comparison of ultrasonic and cold scissor dissection on cavernous nerve function. J Urol. 2009; 181: 2760-6.

22. Dangle PP, Shah KK, Kaffenberger B, Patel VR: The use of high resolution optical coherence tomography to evaluate robotic radical prostatectomy specimens. Int Braz J Urol. 2009; 35: 344-53.

23. Kaul S, Bhandari A, Hemal A, Savera A, Shrivastava A, Menon M: Robotic radical prostatectomy with preservation of the prostatic fascia: a feasibility study. Urology. 2005; 66: 1261-5.

24. Menon M, Tewari A, Peabody J; VIP Team: Vattikuti Institute prostatectomy: technique. J Urol. 2003; 169: 2289-92.

25. Menon M, Shrivastava A, Kaul S, Badani KK, Fumo M, Bhandari M, et al.: Vattikuti Institute prostatectomy: contemporary technique and analysis of results. Eur Urol. 2007; 51: 648-57; discussion 657-8.

26. Menon M, Shrivastava A, Bhandari M, Satyanarayana R, Siva S, Agarwal PK: Vattikuti Institute prostatectomy: technical modifications in 2009. Eur Urol. 2009; 56: 89-96.

27. Patel VR, Shah K, Palmer KJ, Thaly R, Coughlin G: Robotic-assisted laparoscopic radical prostatectomy: a report of the current state. Expert Rev Anticancer Ther. 2007; 7: 1269-78.

28. Chien GW, Mikhail AA, Orvieto MA, Zagaja GP, Sokoloff MH, Brendler CB, et al.: Modified clipless antegrade nerve preservation in robotic-assisted laparoscopic radical prostatectomy with validated sexual function evaluation. Urology. 2005; 66: 419-23.

29. Zorn KC, Gofrit ON, Orvieto MA, Mikhail AA, Zagaja GP, Shalhav AL: Robotic-assisted laparoscopic prostatectomy: functional and pathologic outcomes with interfascial nerve preservation. Eur Urol. 2007; 51: 755-62; discussion 763 .

30. Ahlering TE, Eichel L, Chou D, Skarecky DW: Feasibility study for robotic radical prostatectomy cautery-free neurovascular bundle preservation. Urology. 2005; 65: 994-7.

31. Rodriguez E Jr, Finley DS, Skarecky D, Ahlering TE: Single institution 2-year patient reported validated sexual function outcomes after nerve sparing robot assisted radical prostatectomy. J Urol. 2009; 181: 259-63.
32. Gill IS, Ukimura O, Rubinstein M, Finelli A, Moinzadeh A, Singh D, et al.: Lateral pedicle control during laparoscopic radical prostatectomy: refined technique. Urology. 2005; 65: 23-7.

33. Guru KA, Perlmutter AE, Butt ZM, Peabody JO: Hydrodissection for preservation of neurovascular bundle during robot-assisted radical prostatectomy. Can J Urol. 2008; 15: 4000-3.

34. Bentas W, Wolfram M, Jones J, Bräutigam R, Kramer W, Binder J: Robotic technology and the translation of open radical prostatectomy to laparoscopy: the early Frankfurt experience with robotic radical prostatectomy and one year follow-up. Eur Urol. 2003; 44: $175-81$.

35. Ahlering TE, Kaplan AG, Yee DS, Skarecky DW: Prostate weight and early potency in robot-assisted radical prostatectomy. Urology. 2008; 72: 1263-8.

36. Mendiola FP, Zorn KC, Mikhail AA, Lin S, Orvieto MA, Zagaja GP, et al.: Urinary and sexual function outcomes among different age groups after robot-assisted laparoscopic prostatectomy. J Endourol. 2008; 22: 519-24.

37. Mottrie A, Van Migem P, De Naeyer G, Schatteman P, Carpentier P, Fonteyne E: Robot-assisted laparoscopic radical prostatectomy: oncologic and functional results of 184 cases. Eur Urol. 2007; 52: 746-50.

38. Madeb R, Golijanin D, Knopf J, Vicente I, Erturk E, Patel HR, et al.: Patient-reported validated functional outcome after extraperitoneal robotic-assisted nervesparing radical prostatectomy. JSLS. 2007; 11: 4438.

39. van der Poel HG, de Blok W: Role of extent of fascia preservation and erectile function after robot-assisted laparoscopic prostatectomy. Urology. 2009; 73: 81621.

40. Murphy DG, Kerger M, Crowe H, Peters JS, Costello AJ: Operative details and oncological and functional outcome of robotic-assisted laparoscopic radical prostatectomy: 400 cases with a minimum of 12 months follow-up. Eur Urol. 2009; 55: 1358-66.

41. Tewari A, Srivasatava A, Menon M; Members of the VIP Team: A prospective comparison of radical retropubic and robot-assisted prostatectomy: experience in one institution. BJU Int. 2003; 92: 205-10.

42. Krambeck AE, DiMarco DS, Rangel LJ, Bergstralh EJ, Myers RP, Blute ML, et al.: Radical prostatectomy for prostatic adenocarcinoma: a matched comparison of open retropubic and robot-assisted techniques. BJU Int. 2009; 103: 448-53.

43. Rocco B, Matei DV, Melegari S, Ospina JC, Mazzoleni F, Errico G, et al.: Robotic vs open prostatectomy in a 
laparoscopically naive centre: a matched-pair analysis. BJU Int. 2009; 5. [Epub ahead of print]

44. Hakimi AA, Blitstein J, Feder M, Shapiro E, Ghavamian R: Direct comparison of surgical and functional outcomes of robotic-assisted versus pure laparoscopic radical prostatectomy: singlesurgeon experience. Urology. 2009; 73: 119-23.

45. Berryhill R Jr, Jhaveri J, Yadav R, Leung R, Rao S, El-Hakim A, et al.: Robotic prostatectomy: a review of outcomes compared with laparoscopic and open approaches. Urology. 2008; 72: 1523.

46. Ficarra V, Novara G, Artibani W, Cestari A, Galfano A, Graefen M, et al.: Retropubic, laparoscopic, and robot-assisted radical prostatectomy: a systematic review and cumulative analysis of comparative studies. Eur Urol. 2009; 55: 1037 63.

47. Artibani W, Ficarra V, Guillonneau BD: Open to debate. The motion: a robot is needed to perform the best nerve sparing prostatectomy. Eur Urol. 2007; 52: 275-8.

48. Patel VR, Thaly R, Shah K: Robotic radical prostatectomy: outcomes of 500 cases. BJU Int. 2007; 99: 1109-12.
49. Lee DI: Robotic prostatectomy: what we have learned and where we are going. Yonsei Med J. 2009; 50: 177-81.

50. Badani KK, Kaul S, Menon M: Evolution of robotic radical prostatectomy: assessment after 2766 procedures. Cancer. 2007; 110: 1951-8.

51. Berryhill R Jr, Jhaveri J, Yadav R, Leung R, Rao S, El-Hakim A, Tewari A: Robotic prostatectomy: a review of outcomes compared with laparoscopic and open approaches. Urology. 2008; 72: 1523.

52. Shikanov SA, Zorn KC, Zagaja GP, Shalhav AL: Trifecta outcomes after robotic-assisted laparoscopic prostatectomy. Urology. 2009; 74: 619-23.

53. Ficarra V, Novara G, Fracalanza S, D'Elia C, Secco $\mathrm{S}$, Iafrate $\mathrm{M}$, et al.: A prospective, nonrandomized trial comparing robot-assisted laparoscopic and retropubic radical prostatectomy in one European institution. BJU Int. 2009; 104: 534-9.

54. Joseph JV, Vicente I, Madeb R, Erturk E, Patel HR: Robot-assisted vs pure laparoscopic radical prostatectomy: are there any differences? BJU Int. 2005; 96: 39-42.

\section{Correspondence address:}

Dr. Vipul R. Patel

Associate Professor, Department of Urology

University of Central Florida School of Medicine

410 Celebration Place, Suite 200

Celebration, FL 34747, USA

Fax: + 1407 303-4674

E-mail: vipul.patel.md@flhosp.org 


\section{EDITORIAL COMMENT}

The paper is good and its main qualities include the fact that it was well written (in a simple and clear manner) and raised an issue that is still relevant in the field of Urology, which is the sexual outcome of radical prostatectomy.

The authors perform a review that includes the recent history of retropubic radical prostatectomy, starting with the anatomical studies of Walsh and covering the procedure's evolution, including laparoscopic and robotic prostatectomies. They appraise the surgical technique for preservation of the neurovascular bundles (NVB's) with great clarity and present comparative results between the robotic and the other forms of surgery. The strong point of this work is definitely the review of the anatomy and of the contemporary surgical techniques for preservation of the NVB's.

The authors are clear in stating that the results of the robotic surgery are comparable to those

\section{EDITORIAL COMMENT}

Robot-Assisted Laparoscopic Prostatectomy (RALP) is increasingly performed at specialized centers worldwide. The Robot is becoming an important tool for performance of minimally invasive surgical procedures around the world. With gathering experience, the technique has been shown to be feasible and reproducible.

The RALP approach offers the some advantages as laparoscopic surgery as less postoperative pain, fewer analgesics drugs and early mobilization. The magnification of the surgical field and the 3D images, allow a better view during the dissection of the neuro-vascular bundles and the urethro-vesical anastomosis. The procedure has added new hopes of reducing operative times and the learning curve for Minimally Invasive Prostatectomy. obtained through other techniques, retropubic and laparoscopic, maybe presenting a slight advantage regarding the period for return of the erectile function. Although they are deeply involved in the robotic surgery, the Authors do not present definitive results in favor of such technique, which already has 10 years of evolution.

The authors did not convey final solutions or truths about the subject, but they questioned the different criteria that are currently being used in the definition of sexual potency and appointed the need for a standardized criteria on future comparative studies.

\author{
Dr. Lisias N. Castilho \\ Catholic University \\ Campinas, SP, Brazil \\ E-mail:lisias@dglnet.com.br
}

The authors show in this paper an excellent review of Nerve-Sparing techniques and present the potency outcomes after RALP currently available in medical literature.

Although long-term oncological outcomes are not available for the majority of genitourinary malignancies treated by the Minimally Invasive approach, the intermediate-term data are encouraging and comparable to open surgery. Multicentric studies with longer follow-up are necessary.

Dr. Mauricio Rubinstein Section of Urology Federal University of Rio de Janeiro State Rio de Janeiro, RJ, Brazil E-mail: mrubins74@hotmail.com 